\title{
Investigation of the Proarrhythmic Effects of Antidepressants according to QT Interval, QT Dispersion and T Wave Peak-to-End Interval in the Clinical Setting
}

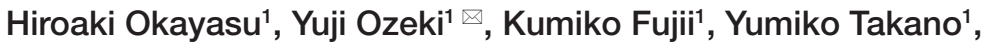 \\ Takahiro Shinozaki ${ }^{1}$, Masami Ohrui ${ }^{2}$, and Kazutaka Shimoda ${ }^{1}$ \\ ${ }^{1}$ Department of Psychiatry, Dokkyo Medical University School of Medicine, Tochigi, Japan \\ ${ }^{2}$ Department of Health Care, Dokkyo Medical University School of Medicine, Tochigi, Japan
}

\begin{abstract}
Objective Some antidepressants have been implicated as risk factors for QT prolongation, which is a predictor of sudden cardiac death. However, the QT interval is considered an imperfect biomarker for proarrhythmic risk. Therefore, we reevaluated the risk of sudden cardiac death due to antidepressants using improved methods, namely, QT dispersion (QTD), T wave peak-to-end interval (Tp-e), and Tp-e/QT ratio.

Methods We compared the effects of antidepressants on QTc (QT/RR $\left.{ }^{1 / 3}\right)$, QTD, Tp-e, and Tp-e/QT ratio in 378 patients with mood disorder. We also compared each index between 165 healthy controls and 215 randomly selected age-matched patients.

Results Age $(\mathrm{p}<0.01)$, sex $(\mathrm{p}<0.05)$, tricyclic antidepressant (TCA) use $(\mathrm{p}<0.05)$, and clomipramine $(\mathrm{p}<0.01)$ and mianserin $(\mathrm{p}<0.05)$ use in particular, significantly associated with a prolonged QTc. We also found that age $(p<0.01)$, TCA use $(p<0.05)$, and clomipramine $(\mathrm{p}<0.01)$ and mianserin $(\mathrm{p}<0.05)$ use in particular, significantly prolonged QTD. However, there was no correlation between each variable and Tp-e or Tp-e/QT ratio. Significant differences in QTc and QTD were found between the patients and healthy controls.

Conclusion From our results, prediction of risk of sudden cardiac death by QTD, Tp-e, or Tp-e/QT ratio was inconsistent. Increased QTD may be more suitable for predicting sudden cardiac death due to antidepressants.

Psychiatry Investig 2019;16(2):159-166
\end{abstract}

Key Words Antidepressants, Sudden cardiac death, QT prolongation, QT dispersion, T peak-to-end, Arrhythmia.

\section{INTRODUCTION}

Antidepressants are reported to increase the incidence of sudden cardiac death. ${ }^{1}$ A study of 14,784 patients with no history of cardiovascular disease who were followed for 8 years revealed that the use of tricyclic antidepressants (TCAs) but not selective serotonin reuptake inhibitors (SSRIs) increased the mortality rate due to cardiovascular disease. ${ }^{2}$ In contrast, Whang et al. ${ }^{3}$ found that SSRI use could be a risk factor for sudden cardiac death.

\footnotetext{
Received: September 28, 2018 Revised: December 3, 2018

Accepted: December 11, 2018

$\triangle$ Correspondence: Yuji Ozeki, MD, PhD

Department of Psychiatry, Dokkyo Medical University School of Medicine, 880 Kitakobayashi, Mibu-machi, Shimotsuga, Tochigi 321-0293, Japan

Tel: +81-282-86-1111, Fax: +81-282-86-5187

E-mail: ozeki@dokkyomed.ac.jp

(a) This is an Open Access article distributed under the terms of the Creative Commons Attribution Non-Commercial License (https://creativecommons.org/licenses/by$\mathrm{nc} / 4.0$ ) which permits unrestricted non-commercial use, distribution, and reproduction in any medium, provided the original work is properly cited.
}

QT interval on electrocardiography (ECG) indicates both ventricular depolarization and repolarization times and varies inversely with the heart rate. Therefore, rate related (corrected) QT interval, QTc, can be calculated. Evaluation of QT interval is a crucial factor for preventing sudden cardiac death because prolonged QT interval is a risk factor for torsade de points. ${ }^{4}$ In most reports, QT interval prolongation is used to assess the risk of sudden cardiac death. TCA use has been implicated as a risk factor for QT interval prolongation. ${ }^{5}$ In addition, some SSRIs also prolong the QT interval, particularly citalopram; a meta-analysis also showed that SSRIs can prolong the QT interval. ${ }^{6}$

Nonetheless, the QT interval is recognized as an imperfect biomarker of proarrhythmic risk. ${ }^{7}$ The QT interval varies according to the ECG context. Continuous measurements of the QT interval from 24-h ECG recordings show QT interval instability. ${ }^{8}$ Furthermore, QT interval is prolonged during sleep. ${ }^{9}$ Nevertheless, the effects of antipsychotic drugs can be assessed by using several variables, such as the $\mathrm{T}$ wave 
peak-to-end interval (Tp-e) and Tp-e/QT ratio, which are considered better predictors of ventricular arrhythmia than QTc. ${ }^{10} \mathrm{Tp}$-e represents a dispersion transmural repolarization time. Several experimental and clinical studies have suggested the utility of Tp-e as a marker of risk in arrhythmia syndromes including congenital long QT syndrome. ${ }^{11,12}$ Another study examined Tp-e using a computer model of rabbit heart ventricles and concluded that Tp-e corresponds to global dispersion of repolarization. ${ }^{13} \mathrm{Tp}$-e is considered more useful than QTc and its dispersion for predicting cardiac arrhythmias in some clinical conditions. ${ }^{14}$

Tp-e/QT ratio has been proposed as a more sensitive index of arrhythmia risk because it eliminates the confounding effects of heart rate and QT interval variability. ${ }^{10} \mathrm{Tp}$-e/ QT ratio can predict cardiac arrhythmias ${ }^{15}$ and includes the values of transmural dispersion (Tp-e) and spatial dispersion (QT interval) of ventricular repolarization. Yamaguchi et al. ${ }^{12}$ evaluated 27 patients with long QT syndrome. These patients were divided into two groups, one comprising patients with Torsades de pointes $(\mathrm{n}=27)$ and the other without this condition $(\mathrm{n}=15)$. QT dispersion (QTD) values were $112 \pm 64 \mathrm{~ms}$ and $70 \pm 40 \mathrm{~ms}$ in the first and second groups, respectively ( $\mathrm{p}=$ 0.0456). The authors also evaluated $\mathrm{Tp}-\mathrm{e}$, revealing $\mathrm{Tp}$-e values in V5 of $185 \pm 46 \mathrm{~ms}$ and $84 \pm 18 \mathrm{~ms}$ in first and second groups, respectively $(\mathrm{p}<0.0001)$. Tp-e differed significantly more than the QTD between patients with and without Torsades de Pointes. Moreover, Tp-e was prolonged and constituted an arrhythmogenic index in patients with long QT syndrome in other studies. ${ }^{11,16}$ In the same study by Yamaguchi et al., ${ }^{12}$ a Tp-e/QT ratio in V5 exceeding 0.28 was also associated with risk of developing Torsades de Pointes.

QTD which is dispersion of QT interval on 12-lead ECG has been advocated as a predictor of cardiovascular mortality. ${ }^{17}$ This variable comprises the interlead difference between the shortest and longest QTc interval on 12-lead surface ECG and has been recommended as a surrogate marker for risk of arrhythmia, in addition to QT interval. ${ }^{18}$ QTD distinguishes between individuals with ventricular arrhythmias and those without. ${ }^{19}$ Recently published data show that, in healthy individuals, QTD $>58 \mathrm{~ms}$ increases the risk of cardiovascular mortality by 3.2-fold and that those with QTD $\geq 80 \mathrm{~ms}$ have 4-fold higher risk of cardiac death than patients with QTD values $<30 \mathrm{~ms}^{20} \mathrm{QTD}$ is commonly considered a reflection of transmural cardiac repolarization expressed through a surface 12-lead ECG. ${ }^{15}$

Therefore, we sought to reevaluate the risk of sudden cardiac death due to antidepressant use by using these improved evaluation methods, namely, Tp-e, Tp-e/QT ratio, and QTD.

\section{METHODS}

\section{Subjects}

Data for 412 patients treated with antidepressants at Dokkyo Medical University School of Medicine and Fudougaoka Hospital between 2007 and 2015 were reviewed for medical history, ECG, serum potassium level, and liver and kidney function tests. Among these 412 patients, 2 patients receiving treatment for hyperthyroidism, 10 with atrial fibrillation, 2 with history of cardiac infarction, and 20 with hypokalemia $(<3.5 \mathrm{mEq} / \mathrm{L})$ were excluded because these factors are well-known risk factors for QTc prolongation. Data from the remaining 378 patients (130 males, 248 females; age range, $20-87$ years; mean age $54.2 \pm 16.2$ years) were examined in this study. Table 1 shows the distribution of medication and dosage.

Psychiatric diagnoses were made based on the Diagnostic and Statistical Manual of Mental Disorders, 4th Edition, Text Revision, or 5th Edition. In total, 298 patients were diagnosed with major depressive disorder, 52 with bipolar disorder, and 28 with other depressive disorders (Table 1). All patients underwent ECG to evaluate their physical condition and pharmacotherapy status. Finally, 165 healthy volunteers who had undergone routine health checkups between 2010 and 2012 at Dokkyo Medical University Hospital, Japan, were recruited to this investigation. These participants had no physical abnormalities or abnormal laboratory data. All participants were measured using the same device of ECG and each index (QTc, QTD, and Tp-e) was investigated by the same person in order to guarantee the identity of the results.

Standard 12-lead ECG was recorded at a paper speed of $25 \mathrm{~mm} / \mathrm{s}$. The QT interval was measured manually according to a previous report. ${ }^{21}$ The end of the $\mathrm{T}$ wave was determined as the intersection between the tangent to the steepest downslope of the T-wave and the isoelectric line. The QT interval was then "corrected" as a value that varies in relation to heart rate. Several methods for correcting QT interval by heart rate have been proposed, each with distinctive characteristics. In the present study, we used Fridericia's formula $\left(\mathrm{QTc}=\mathrm{QT} / \mathrm{RR}^{1 / 3}\right)$ because it is considered more appropriate than Bazett's formula $\left(\mathrm{QTc}=\mathrm{QT} / \mathrm{RR}^{1 / 2}\right)$ in cases with tachycardia or bradycardia. ${ }^{22,23}$

QTD was calculated as the difference between the maximum and the minimum QT intervals on 12-lead ECG. If the height or depth of the $\mathrm{T}$ wave was less than $1.5 \mathrm{~mm}$, that lead was excluded from analysis. A limit of six or more leads per ECG was arbitrarily chosen to exclude ECGs of inadequate technical quality from analysis. ${ }^{24} \mathrm{Tp}$-e was measured from $\mathrm{T}$ peak to $\mathrm{T}$ end. Tp-e and QT intervals were measured in lead V5. If V5 was not suitable, leads V4 and V6 were used, in 
Table 1. Demographic data of patients and distribution of medication and dosage

\begin{tabular}{|c|c|c|c|c|}
\hline & Male & Female & Total & \\
\hline No. of patient & 130 & 248 & 378 & \\
\hline Mean age (SD) & $50.5(14.5)$ & $56.1(16.7)$ & $54.2(16.2)$ & \\
\hline Diagnosis & No. of patient (\%) & No. of patient (\%) & No. of patient (\%) & \\
\hline Major depressive disorder & $98(25.9)$ & $200(52.9)$ & $298(78.8)$ & \\
\hline Bipolar I disorder & $14(3.70)$ & $15(3.97)$ & $29(7.67)$ & \\
\hline Bipolar II disorder & $6(1.59)$ & $17(4.50)$ & $23(6.08)$ & \\
\hline Other depressive disorder & $12(3.17)$ & $16(4.23)$ & $28(7.41)$ & \\
\hline Administered drugs & $\begin{array}{c}\text { Male } \\
\text { No. of prescription } \\
(\%)\end{array}$ & $\begin{array}{c}\text { Female } \\
\text { No. of prescription } \\
(\%)\end{array}$ & $\begin{array}{c}\text { Total } \\
\text { No. of prescription } \\
(\%)\end{array}$ & $\begin{array}{c}\text { Mean dose (SD), } \\
\text { mg }\end{array}$ \\
\hline Antidepressants & $110(29.1)$ & $215(56.9)$ & $325(86.0)$ & 140.3 (89.0): imipramine equivalent dose \\
\hline TCA & $49(13.0)$ & $76(20.1)$ & $125(33.1)$ & 105.8 (64.6): imipramine equivalent dose \\
\hline Non-TCA & $126(33.3)$ & $132(34.9)$ & $258(68.3)$ & 135.5 (84.6): imipramine equivalent dose \\
\hline Imipramine & $2(0.53)$ & $4(1.06)$ & $6(1.59)$ & $35.8(21.3)$ \\
\hline Clomipramine & $17(4.50)$ & $20(5.29)$ & $37(9.79)$ & $104.1(50.7)$ \\
\hline Amitriptyline & $10(2.65)$ & $22(5.82)$ & $32(8.47)$ & $74.2(46.9)$ \\
\hline Nortriptyline & $8(2.12)$ & $12(3.17)$ & $20(5.29)$ & $62.0(39.1)$ \\
\hline Amoxapine & $15(3.97)$ & $22(5.82)$ & $37(9.79)$ & $81.4(40.0)$ \\
\hline Mianserin & $23(6.08)$ & $34(8.99)$ & $57(15.1)$ & $16.6(11.4)$ \\
\hline Maprotiline & $4(1.06)$ & $2(0.53)$ & $6(1.59)$ & $67.8(34.6)$ \\
\hline Trazodone & $10(2.65)$ & $20(5.29)$ & $30(7.94)$ & $60.8(48.2)$ \\
\hline Fluvoxamine & $2(0.53)$ & $17(4.50)$ & $19(5.03)$ & $89.5(37.4)$ \\
\hline Paroxetine & $12(3.17)$ & $28(7.41)$ & $40(10.6)$ & $23.3(11.6)$ \\
\hline Sertraline & $6(1.59)$ & $10(2.65)$ & $16(4.23)$ & $56.3(28.6)$ \\
\hline Escitalopram & $11(2.91)$ & $16(4.23)$ & $27(7.14)$ & $16.3(4.83)$ \\
\hline Duloxetine & $6(1.59)$ & $18(4.76)$ & $24(6.35)$ & $41.7(14.0)$ \\
\hline Milnacipran & $22(5.82)$ & $33(8.73)$ & $55(14.6)$ & $71.5(38.4)$ \\
\hline Mirtazapine & $17(4.50)$ & $42(11.1)$ & $59(15.6)$ & $25.6(11.7)$ \\
\hline \multicolumn{5}{|l|}{ Mood stabilizers } \\
\hline Lithium & $25(6.61)$ & $31(8.20)$ & $56(14.8)$ & $464.3(221.5)$ \\
\hline Carbamazepine & $2(0.53)$ & $12(3.17)$ & $14(3.70)$ & $386.4(194.8)$ \\
\hline Sodium valproate & $17(4.50)$ & $26(6.88)$ & $43(11.4)$ & $541.9(287.9)$ \\
\hline Lamotrigine & $8(2.12)$ & $19(5.03)$ & $27(7.14)$ & $139.4(109.1)$ \\
\hline Antipsychotics & $77(20.4)$ & $72(19.0)$ & $149(39.4)$ & 177.0 (177.7): chlorpromazine equivalent dose \\
\hline Benzodiazepines & $99(26.2)$ & $217(57.4)$ & $316(83.6)$ & 17.5 (21.3): diazepam equivalent dose \\
\hline Antiparkinsonian drugs & $6(1.59)$ & $13(3.44)$ & $19(5.03)$ & 2.43 (2.07): biperiden equivalent dose \\
\hline
\end{tabular}

TCA: tricyclic antidepressant, SD: standard deviation

that order. ${ }^{25} \mathrm{Tp}-\mathrm{e} / \mathrm{QT}$ ratio was calculated as the ratio of Tp-e in that lead to the corresponding QT interval. ${ }^{26}$

In our approved method, written informed consent was not required from participants.

\section{Ethics}

The protocol for this study was approved by the ethics committees of the Dokkyo Medical University School of Medicine (approval number: 25024). To All clinical records used in this study were anonymized by removing any identifying information (such as name and registration number). Furthermore, the clinical data were collated and managed by one person. The person who performed statistical analysis could not access the original data of each participant. The 
past patients' data was used for understanding this issue. And healthy controls underwent the examinations voluntarily. No children (under 20 years of age) were included in the study.

\section{Statistical analysis}

For the first analysis, linear regression analysis was applied to examine risk factors for QTc lengthening, QTD increase, Tp-e lengthening, or Tp-e/QT ratio increase. Age, sex, antidepressant dose (imipramine equivalent), antipsychotic dose (chlorpromazine equivalent), benzodiazepine dose (diazepam equivalent), and antiparkinsonian drug dose (biperiden equivalent) were included in the stepwise regression model. In the second analysis, age, sex, and individual antidepressant dose were entered as independent variables in the linear regression analysis with stepwise model reduction.

In the third analysis, QTc, QTD, Tp-e, and Tp-e/QT ratio were compared between patients who were prescribed antidepressants and healthy controls by analysis of covariance. These analyses were adjusted for age and sex. Using a general linear model, we compared QTc, QTD, Tp-e, and Tp-e/QT ratio between 165 healthy volunteers (64 males, mean age $56.7 \pm 9.4$ years) and 215 randomly selected age-matched patients (64 males, mean age 56.7 \pm 9.1 years) treated with antidepressants.

All statistical analyses were performed using SPSS version 13.0 (SPSS Japan, Inc., Tokyo, Japan). All reported $\mathrm{p}$ values are two-tailed, and statistical significance was set at $\mathrm{p}<0.05$.

\section{RESULTS}

\section{QTc}

In the first analysis, age [partial regression coefficient $(\mathrm{PRC})=$ $0.319,95 \% \mathrm{CI}=0.132-0.506, \mathrm{p}<0.01]$, sex $(\mathrm{PRC}=6.66,95 \%$ $\mathrm{CI}=0.376-12.9, \mathrm{p}<0.05)$, and TCAs $(\mathrm{PRC}=9.56,95 \% \mathrm{CI}=$ 4.72-14.4, p<0.05) were positively correlated with QTc (Fridericia's formula) (Table 2). In the second analysis, age (PRC= 0.279, 95\% CI $=0.0954-0.463, \mathrm{p}<0.01)$, sex $(\mathrm{PRC}=6.41,95 \%$ $\mathrm{CI}=0.175-12.6, \mathrm{p}<0.05)$, clomipramine $(\mathrm{PRC}=19.4,95 \% \mathrm{CI}=$ 9.19-29.6, $\mathrm{p}<0.01)$, and mianserin $(\mathrm{PRC}=25.7,95 \% \mathrm{CI}=$ $1.96-49.5, \mathrm{p}<0.05$ ) were correlated with QTc (Fridericia's formula) (Table 3).

\section{QTD}

In the first analysis, age ( $\mathrm{PRC}=0.319,95 \% \mathrm{CI}=0.182-$ 0.456, $\mathrm{p}<0.01$ ), and TCAs (PRC $=5.50,95 \% \mathrm{CI}=1.94-9.06$, $\mathrm{p}<0.05$ ) were positively correlated with QTD (Table 2 ). In the second analysis, age ( $\mathrm{PRC}=0.299,95 \% \mathrm{CI}=0.166-0.433$, $\mathrm{p}<0.01$ ), clomipramine $(\mathrm{PRC}=13.3,95 \% \mathrm{CI}=5.82-20.8, \mathrm{p}<$ $0.01)$, and mianserin $(\mathrm{PRC}=17.8,95 \% \mathrm{CI}=0.348-35.3, \mathrm{p}<$

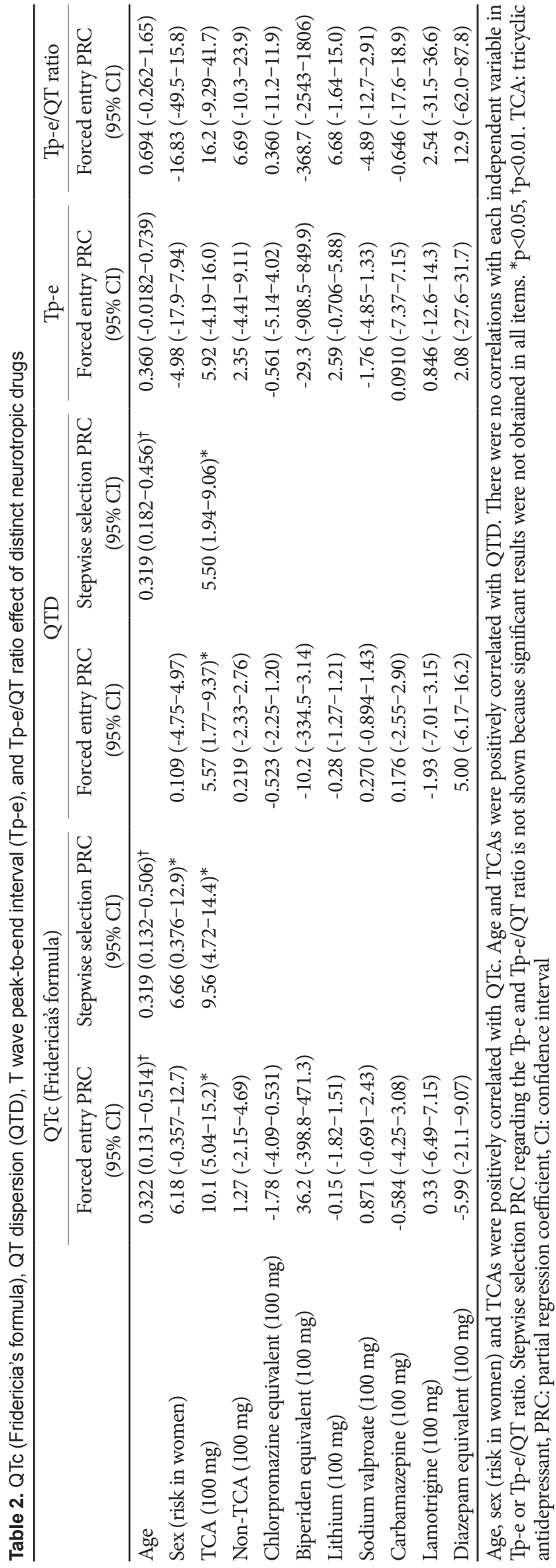




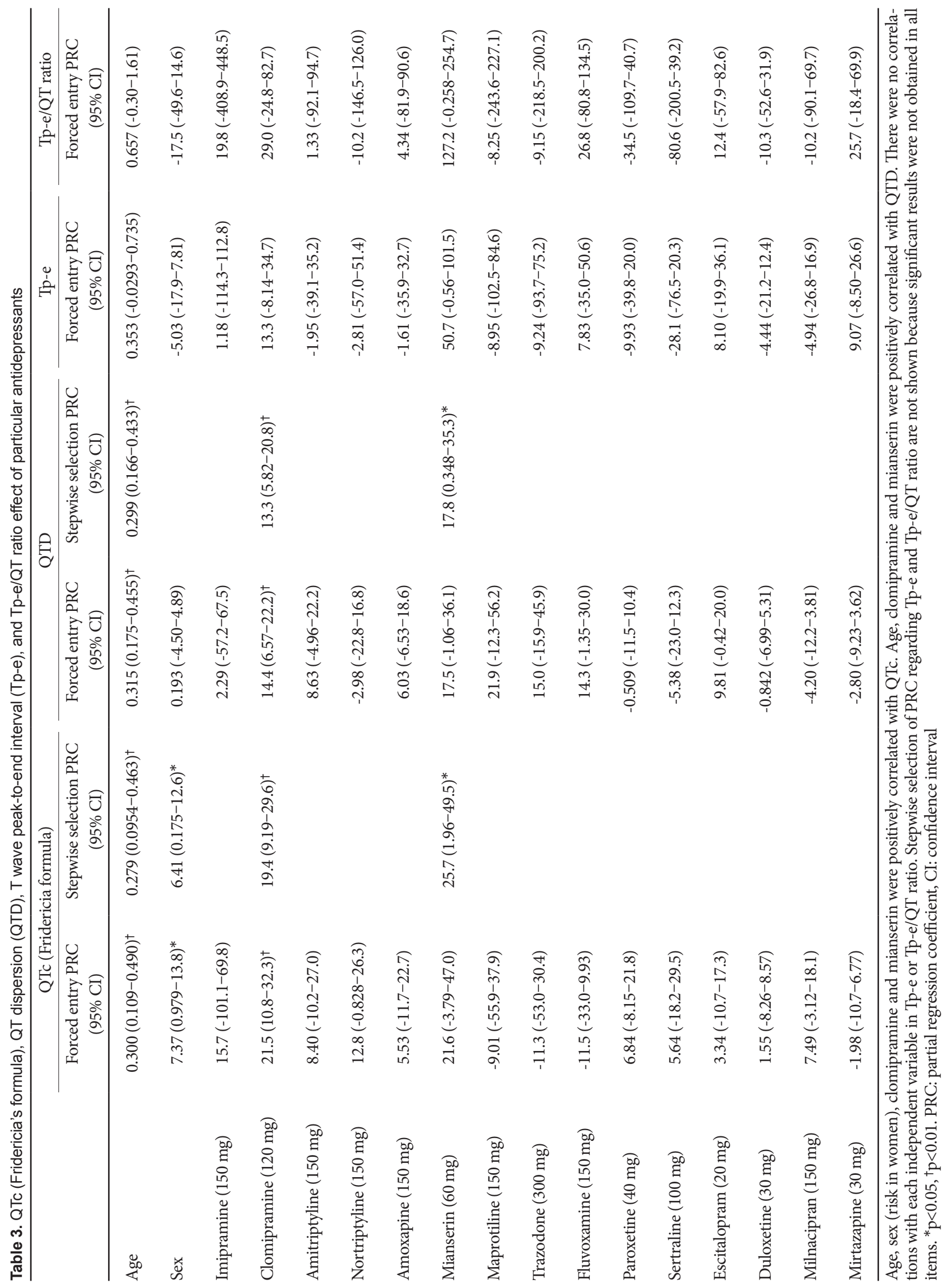


0.05) were correlated with QTD (Table 3).

\section{Tp-e}

The first and second analysis showed no correlation between each independent variable and Tp-e interval (Table 2 and 3).

\section{Tp-e/QT ratio}

In the first and second analysis there was no correlation between each independent variable and Tp-e/QT ratio (Table 2 and 3 ).

\section{Comparison between patients prescribed antidepressants and healthy controls}

In the third analysis, significant differences in QTc (F value $17.85, \mathrm{p}<0.001)$ and QTD (F value 6.679, $\mathrm{p}<0.010$ ) were found between patients and healthy controls. However, there was no different in age, sex, Tp-e and Tp-e/QT between the patients and healthy controls (Table 4).

\section{DISCUSSION}

QTD was correlated with antidepressant dose, especially for clomipramine and mianserin, unlike Tp-e and Tp-e/QT ratio. Compared with healthy controls, QTD was increased in patients. However, Tp-e and Tp-e/QT ratio were not longer than those of normal controls.

Although there is no consensus on the normal range of Tp-e values and further research is needed to define them ${ }^{15}$ a previous report states mean Tp-e values of healthy individuals in the V5 lead as $94 \pm 10 \mathrm{~ms}$ in men and $92 \pm 11 \mathrm{~ms}$ in women. ${ }^{27}$ Our results were $87.1 \pm 16.6 \mathrm{~ms}$ in healthy men and $90.0 \pm 72.5 \mathrm{~ms}$ in healthy women.

Reported normal QTD values are $33.4 \pm 20.0 \mathrm{~ms}$, with a range of $10.5 \pm 10.0 \mathrm{~ms}$ to $71 \pm 7.0 \mathrm{~ms}$ and a median of $37 \mathrm{~ms}^{28}$ In our study, mean QTD was $50.4 \pm 17.4 \mathrm{~ms}$ in the healthy

Table 4. Comparison of QT dispersion (QTD), T wave peak-to-end interval (Tp-e), and Tp-e/QT between patients treated with drugs and healthy controls

\begin{tabular}{lcc}
\hline & F value & p value \\
\hline Age & 0.705 & 0.402 \\
Sex & 0.002 & 0.961 \\
QTc (Fridericia's formula) & 17.85 & $<0.001^{\dagger}$ \\
QT dispersion & 6.679 & $0.010^{*}$ \\
Tp-e & 2.971 & 0.086 \\
Tp-e/QT & 3.294 & 0.070 \\
\hline
\end{tabular}

Significant differences in QTc and QTD were found between patients and healthy controls. There were no different in age, sex, Tp-e and Tp-e/QT ratio between the patients and healthy controls. ${ }^{*} \mathrm{p}<0.05$, ${ }^{\dagger} \mathrm{p}<0.01$ controls.

Tp-e/QT ratio measured in healthy populations in precordial lead V5, which best reflects the transmural axis of the left ventricle, has a mean value of $0.21 \pm 0.03$ and a range of 0.15 to $0.25 .{ }^{10}$ In our study, mean Tp-e/QT ratio was $0.232 \pm$ 0.146 in the healthy controls.

In a previous consideration of the QT prolongation effects of antidepressants, we that found TCAs induce QT interval prolongation. ${ }^{29}$ Regarding individual drugs, clomipramine and amitriptyline significantly prolonged QT interval. A similar result was found for QTD, induced by TCAs, as well as clomipramine. Unlike amitriptyline, a significant relationship was found between QTD and mianserin, but Tp-e and Tp-e/QT were not correlated with any factors. Increased QTD has been proposed as surface ECG markers of vulnerability to ventricular arrhythmias and potential predictors of mortality. ${ }^{17}$ QTD, a more accurate predictive factor, also indicated the risk of sudden cardiac death associated with TCAs. However, considering both Tp-e and Tp-e/QT ratio, no risk factor investigated in this study was identified as an indicator.

QT interval has been correlated with particular doses of antidepressants. ${ }^{30}$ In that report, a total of 1,472,965 valid QTc measurements were obtained from patients receiving a prescription of interest and 38,397 had an electrocardiogram within the 14- to 90-day window. Age, race, sex, insurance, year of electrocardiogram, history of major depression, history of myocardial infarction, history of ventricular arrhythmia, history of hypertension, history of hyperlipidemia, and the Charlson comorbidity index score were all significantly associated with QTc interval $(\mathrm{p}<0.01)$. For each medication of interest, dose-QTc curves were analyzed for the dose-response relationship using a linear model adjusted for features associated with QTc. Dose was found to be a significant predictor of QTc for citalopram [adjusted beta 0.10 (SE 0.04), $\mathrm{p}<0.01$ ], escitalopram [adjusted beta $0.58(0.15), \mathrm{p}<0.001$ ], and amitriptyline [adjusted beta $0.11(0.03), \mathrm{p}<0.001$ ]. When the dose was a significant predictor of QTc, post hoc pairwise tests were performed to compare each dose interval. Escalating doses with significant increases in QTc were observed for citalopram $10 \mathrm{mg}$ to $20 \mathrm{mg}$ [adjusted beta 9.8 (SE 1.6), p< 0.001 ], citalopram $40 \mathrm{mg}$ to $60 \mathrm{mg}$ [adjusted beta 6.1 (2.1), $\mathrm{p}<0.01$ ], escitalopram $5 \mathrm{mg}$ to $10 \mathrm{mg}$ [adjusted beta 11.0 (4.5), $\mathrm{p}<0.05$ ], escitalopram $10 \mathrm{mg}$ to $20 \mathrm{mg}$ [adjusted beta 4.7 (1.6), $\mathrm{p}<0.01$ ], and amitriptyline $25 \mathrm{mg}$ to $50 \mathrm{mg}$ [adjusted beta 3.4 (1.4), $\mathrm{p}<0.05]$.

Regarding clomipramine, the methods applied in our study also indicate an increased risk of sudden cardiac death. However, no such risk was for escitalopram. This discrepancy could be due to the small number of subjects or their ethnicity. A review by Jasiak and Bostwick ${ }^{31}$ pointed out that dulox- 
etine does not prolong QT interval at clinical doses and that mirtazapine has low potential for increasing QT interval. Our evaluation also indicated the low proarrhythmic potential of both these medications.

In our study, prediction of the risk of sudden cardiac death by QTD, Tp-e, or Tp-e/QT ratio was inconsistent, particularly the results for QTD and Tp-e. However, it is not clear whether QTD or Tp-e better predicts fatal arrhythmia. QTD indicates dispersion of surface depolarization, whereas Tp-e represents transmural repolarization. Therefore, QTD and Tp-e each have different physiological implications. Antidepressants may affect cardiac physiological mechanisms, which can only be evaluated by QTD. Thus, QTD might be more suitable for predicting sudden cardiac death due to antidepressant use. However, QTD and QT interval could unduly predict sudden cardiac death, even though antidepressants could be a risk factor. Contrary to these considerations, QTD or QT interval might overestimate the risk of sudden cardiac death. Therefore, to reach a firm conclusion on this matter, largescale cohort studies are required.

There are several limitations to this study. First, because we evaluated real-world patients retrospectively, we could not evaluate changes in QTD, Tp-e, and Tp-e/QT ratio before and after medication use in the same patient. Second, we could not adjust for the time of measurement of ECG. Third, we compared QTD, Tp-e, and Tp-e/QT ratio between patients treated with drugs and healthy controls, but these were not comparisons between medication-naïve mood disorder patients and healthy patients.

\section{Acknowledgments}

Kazutaka Shimoda has received research support from Meiji Seika Pharma Co., Pfizer Inc., Dainippon Sumitomo Pharma Co., Ltd., Daiichi Sankyo Co., Otsuka Pharmaceutical Co., Ltd., Astellas Pharma Inc., Novartis Pharma K.K., Eisai Co., Ltd., Takeda Pharmaceutical Co., Ltd. and honoraria from Mitsubishi Tanabe Pharma Corporation, Meiji Seika Pharma Co., Ltd., Dainippon Sumitomo Pharma Co., Ltd., Takeda Pharmaceutical Co., Shionogi \& Co., Ltd., Daiichi Sankyo Co., Pfizer Inc. and Eisai Co., Ltd. The authors other than Kazutaka Shimoda declare no biomedical or financial interests or potential conflicts of interest directly relevant to the content of the present study.

This syudy was supported by a Grant-in-Aid for Scientific Research from the Japan Society for the Promotion of Research (JSPS KAKENHI ) Grant Number JP15K19745.

\section{REFERENCES}

1. Sicouri S, Antzelevitch C. Sudden cardiac death secondary to antidepressant and antipsychotic drugs. Expert Opin Drug Saf 2008;7:181-194.

2. Hamer M, Batty GD, Seldenrijk A, Kivimaki M. Antidepressant medication use and future risk of cardiovascular disease: the Scottish Health Survey. Eur Heart J 2011;32:437-442.

3. Whang W, Kubzansky LD, Kawachi I, Rexrode KM, Kroenke CH, Glynn RJ, et al. Depression and risk of sudden cardiac death and coronary heart disease in women: results from the Nurses' Health Study. J Am Coll Cardiol 2009;53:950-958.

4. Straus SM, Kors JA, De Bruin ML, van der Hooft CS, Hofman A, Hee- ringa J, et al. Prolonged QTc interval and risk of sudden cardiac death in a population of older adults. J Am Coll Cardiol 2006;47:362-367.

5. Reilly JG, Ayis SA, Ferrier IN, Jones SJ, Thomas SH. QTc-interval abnormalities and psychotropic drug therapy in psychiatric patients. Lancet 2000;355:1048-1052.

6. Beach SR, Kostis WJ, Celano CM, Januzzi JL, Ruskin JN, Noseworthy $\mathrm{PA}$, et al. Meta-analysis of selective serotonin reuptake inhibitor-associated QTc prolongation. J Clin Psychiatry 2014;75:e441-e449.

7. ICH Steering Committee. ICH harmonized tripartite guideline. The clinical evaluation of QT/QTC interval prolongation and proarrhythmic potential for non-antiarrhythmic drugs E14. 2005. Available at http://www.ich.org/fileadmin/Public_Web_Site/ICH_Products/Guidelines/Efficacy/E14/E14_Guideline.pdf. Accessed September 28, 2018.

8. Browne KF, Prystowsky E, Heger JJ, Chilson DA, Zipes DP. Prolongation of the Q-T interval in man during sleep. Am J Cardiol 1983;52:55-59.

9. Watanabe J, Suzuki Y, Fukui N, Ono S, Sugai T, Tsuneyama N, et al. Increased risk of antipsychotic-related QT prolongation during nighttime: a 24-hour holter electrocardiogram recording study. J Clin Psychopharmacol 2012;32:18-22.

10. Gupta P, Patel C, Patel H, Narayanaswamy S, Malhotra B, Green JT, et al. T(p-e)/QT ratio as an index of arrhythmogenesis. J Electrocardiol 2008;41:567-574.

11. Lubinski A, Lewicka-Nowak E, Kempa M, Baczynska AM, Romanowska I, Swiatecka G. New insight into repolarization abnormalities in patients with congenital long QT syndrome: the increased transmural dispersion of repolarization. Pacing Clin Electrophysiol 1998;21:172-175.

12. Yamaguchi M, Shimizu M, Ino H, Terai H, Uchiyama K, Oe K, et al. T wave peak-to-end interval and QT dispersion in acquired long QT syndrome: a new index for arrhythmogenicity. Clin Sci 2003;105:671-676.

13. Arteyeva NV, Goshka SL, Sedova KA, Bernikova OG, Azarov JE. What does the T(peak)-T(end) interval reflect? An experimental and model study. J Electrocardiol 2013;46:296. e1-8.

14. Antzelevitch C, Shimizu W. Cellular mechanisms underlying the long QT syndrome. Curr Opin Cardiol 2002;17:43-51.

15. Castro-Torres Y, Carmona-Puerta R, Katholi RE. Ventricular repolarization markers for predicting malignant arrhythmias in clinical practice. World J Clin Cases 2015;3:705-720.

16. Takenaka K, Ai T, Shimizu W, Kobori A, Ninomiya T, Otani H, et al. Exercise stress test amplifies genotype-phenotype correlation in the LQT1 and LQT2 forms of the long-QT syndrome. Circulation 2003;107:838844.

17. Okin PM, Devereux RB, Howard BV, Fabsitz RR, Lee ET, Welty TK. Assessment of QT interval and QT dispersion for prediction of allcause and cardiovascular mortality in American Indians: The Strong Heart Study. Circulation 2000;101:61-66.

18. Molnar J, Somberg JC. QT dispersion: still a useful measurement: Cardiology 2009;112:165-167.

19. Day CP, McComb JM, Campbell RW. QT dispersion: an indication of arrhythmia risk in patients with long QT intervals. Br Heart J 1990;63: 342-344.

20. Elming H, Holm E, Jun L, Torp-Pedersen C, Kober L, Kircshoff M, et al. The prognostic value of the QT interval and QT interval dispersion in all-cause and cardiac mortality and morbidity in a population of Danish citizens. Eur Heart J 1998;19:1391-1400.

21. Charbit B, Samain E, Merckx P, Funck-Brentano C. QT interval measurement: evaluation of automatic QTc measurement and new simple method to calculate and interpret corrected QT interval. Anesthesiology 2006;104:255-260.

22. Bazett $H$. An analysis of the time-relations of electrocardiograms. Heart 1920;7:353-370.

23. Fridericia L. Die Systolendauer im Elektrokardiogramm bei Normalem Menschen und bei Herzkranken. Acta Med Scand 1920;53:469-486.

24. Kamochi H, Nii T, Eguchi K, Mori T, Yamamoto A, Shimoda K, et al. Clarithromycin associated with torsades de pointes. Jpn Circ J 1999;63: 421-422. 
25. Haarmark C, Hansen PR, Vedel-Larsen E, Pedersen SH, Graff C, Andersen MP, et al. The prognostic value of the Tpeak-Tend interval in patients undergoing primary percutaneous coronary intervention for ST-segment elevation myocardial infarction. J Electrocardiol 2009;42: 555-560.

26. Shimizu M, Ino H, Okeie K, Yamaguchi M, Nagata M, Hayashi K, et al. T-peak to T-end interval may be a better predictor of high-risk patients with hypertrophic cardiomyopathy associated with a cardiac troponin I mutation than QT dispersion. Clin Cardiol 2002;25:335-339.

27. Haarmark C, Graff C, Andersen MP, Hardahl T, Struijk JJ, Toft E, et al. Reference values of electrocardiogram repolarization variables in a healthy population. J Electrocardiol 2010;43:31-39.

28. Malik M, Batchvarov VN. Measurement, interpretation and clinical potential of QT dispersion. J Am Coll Cardiol 2000;36:1749-1766.

29. Okayasu H, Ozeki Y, Fujii K, Takano Y, Saeki Y, Hori H, et al. Pharmacotherapeutic determinants for QTc interval prolongation in Japanese patients with mood disorder. Pharmacopsychiatry 2012;45:279-283.

30. Castro VM, Clements CC, Murphy SN, Gainer VS, Fava M, Weilburg JB, et al. QT interval and antidepressant use: a cross sectional study of electronic health records. BMJ 2013;346:2288.

31. Jasiak NM, Bostwick JR. Risk of QT/QTc prolongation among newer non-SSRI antidepressants. Ann Pharmacother 2014;48:1620-1628. 